\title{
Dynamic Analysis of one Continuously Variable Valve Actuation Mechanism based on VALDYN
}

\author{
Qu XiaoZhen \\ School of Automotive and Traffic Engineering \\ Liaoning University of Technology \\ Jinzhou, China
}

\begin{abstract}
A simple mechanical CVVA system as a four-bar linkage mechanism is characterized by compactness, and it offers certain benefits in terms of adaptation to various cylinder head configurations, which is conducive to improve engine performance greatly is introduced in this paper. The CVVA mechanism consists of a four-bar linkage, a rotating first cam and two oscillating second cams in addition to the conventional overhead camshaft valve train system. The construction of the model and the dynamic analysis is also fully proposed in VALDYN software. The simulation results demonstrate that the CVVA mechanism has the capacity to sustain proper performance in the valve lift and valve timing across the whole speed range.
\end{abstract}

Keywords-CVVA; engine performance; dynamic analysis; valve lift; valve timing

\section{INTRODUCTION}

The valve train system is one of important subsystems in the internal combustion engine, which is responsible for performance and power output of engines. As opposed to the conventional valve train systems, in which the valve motion is fixed just as a function of the camshaft angle of rotation [1-2]. The continuously variable valve actuation (CVVA) mechanism can vary the valve open duration and maximum lift continuously, so that to provide greater flexibility in valve event control compared to conventional valve trains [3-9]. In this paper, a simple mechanical CVVA mechanism is proposed, and the dynamic behaviors are described in VALDYN software.

\section{OPERATING PRINCIPLE OF THE CVVA MECHANISM}

The layout and schematic diagram of the CVVA mechanism is shown in Fig .1. The 2 nd cam is pivoted to a control shaft, and the control arm is pivoted to an offset bushing (eccentric cam) that is fixed to the control shaft. When the 1st cam rotates about the fixed axis $(\mathrm{O})$, the control arm has an oscillatory rocker motion around the center of the offset bushing (S). Because the control arm

is pivoted to the eccentric cam, the pivot center of the control arm (S) moves around the center of the control shaft $(\mathrm{F})$ due to the rotation of the control shaft. When the lift phase is selected, the pivot center of the control arm (S) is fixed, and the links in Figure 1 constitute a four-bar linkage F.S.B.E. All components of the CVVA mechanism between the 1st cam and 2nd cams are tightly connected by the four-bar linkage, and they constitute a forced drive mechanism. When the center of the control

\author{
Sun Naizhen \\ School of Automotive and Traffic Engineering \\ Liaoning University of Technology \\ Jinzhou, China
}

arm (S) moves, the initial contact point of the 2nd cam and swing arm roller (D) also changes. Therefore, even if the same 1st cam actuation is applied to the mechanism, the region of the 2nd cam actuation changes, which enables variable valve actuation.

The kinematic analysis of the CVVA mechanism is described in [10]. The variable valve lift is accomplished by changing the control shaft angle (CA) to vary from low lift $(0.72 \mathrm{~mm})$ to high lift $(9.91 \mathrm{~mm})$. In low lift phase, the swing arm roller contacts the base circle of the 2 nd cam in the large portion of the 2 nd cam angle of rotation. Even if the total angle of rotation of the 2 nd cam is similar (regardless of the lift phase), valve lift can be kept small in the low lift phase. In contrast, the swing arm rotates from the beginning of the 2 nd cam rotation in high lift phase.

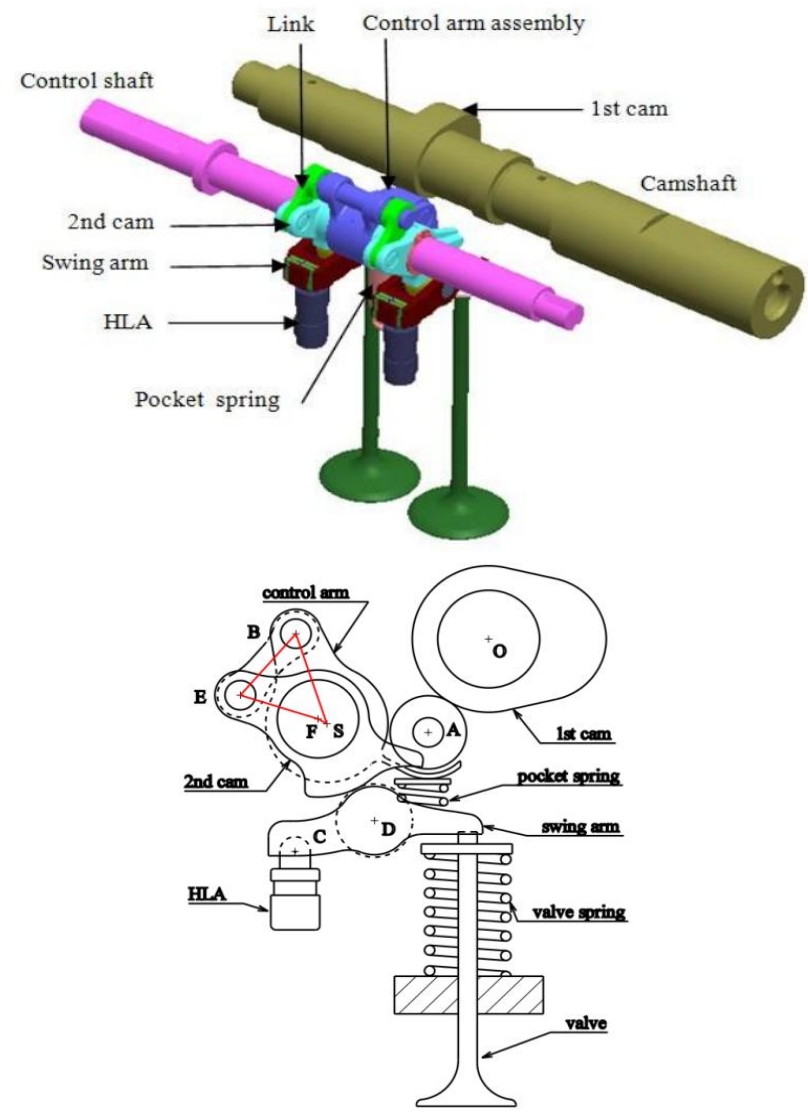

Figure 1. Three-dimensional layout and two-dimensional schematic diagram of the CVVA mechanism 


\section{DYNAMIC MODEL AND DYNAMIC ANALYSIS OF THE CVVA MECHANISM IN VALDYN}

To establish the dynamic model in VALDYN software, some important works must be prepared, such as, the coordinate relations among the components, the contact stiffness and the contact damping between some specific components, the spring parameters and so forth. Then, the dynamic model of the CVVA mechanism is finished in VALDYN as shown in Fig .2, and two typical working conditions of the CVVA mechanism for the low lift phase $(0.72 \mathrm{~mm})$ and the high lift phase $(9.91 \mathrm{~mm})$ are obtained from the dynamic simulation as shown in Fig .3.

The dynamic properties are illustrated by three typical valve lift phases, the low lift phase $(0.72 \mathrm{~mm})$, the middle lift phase $(6.58 \mathrm{~mm})$, the high lift phase $(9.91 \mathrm{~mm})$. Fig .4 shows the low lift phase $(0.72 \mathrm{~mm})$. The comparison of valve lifts between the design and simulation results looks pretty same without considering the camshaft speed. The working condition could cover the idle speed and lower speed of automobile engine, which is better for improving fuel economy of engine.

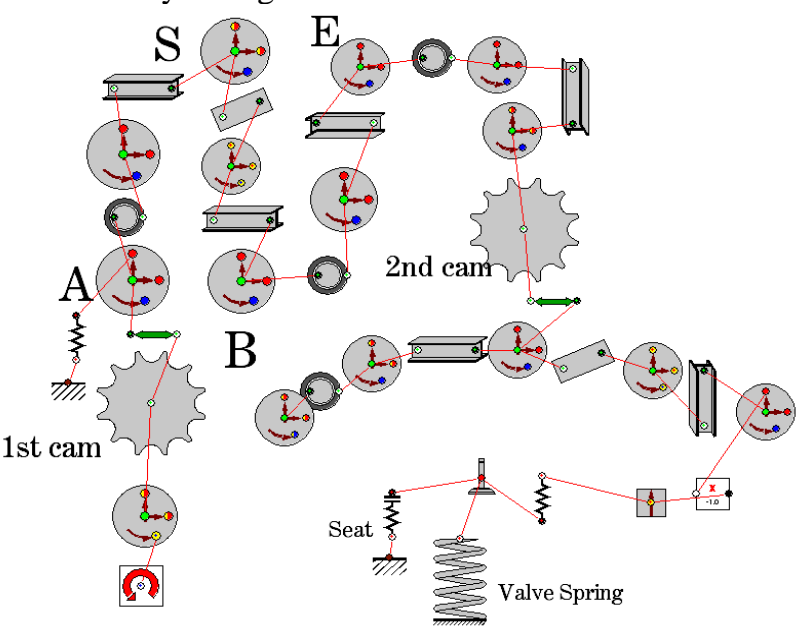

Figure 2. Dynamic model of the CVVA mechanism in VALDYN

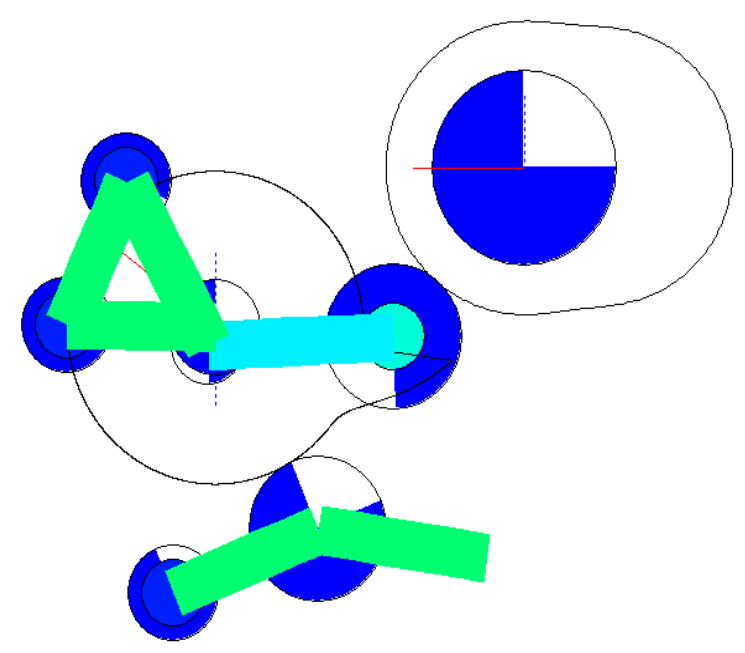

(a) Low lift phase

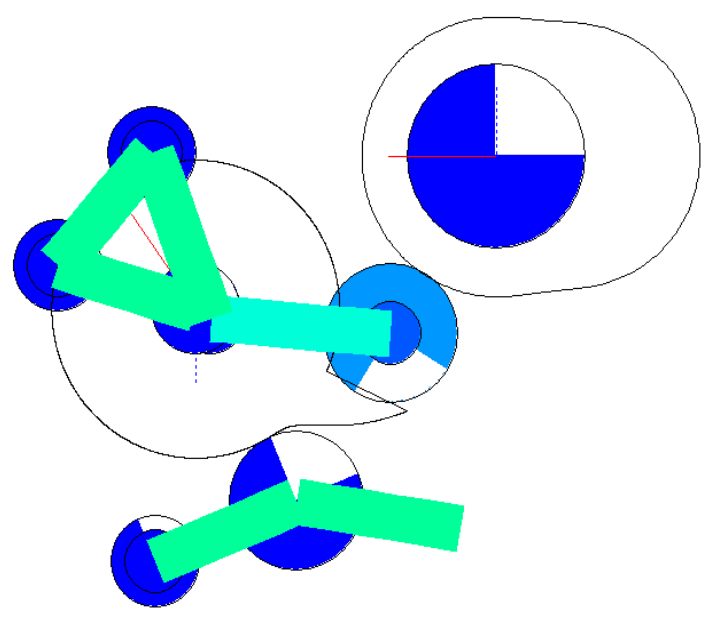

(b) High lift phase

Figure 3. Two typical working conditions of the CVVA mechanism

The good curves of valve lifts illustrate that the camshaft speed could be successfully operated up to 3000 $\mathrm{rpm}$ for the working condition of middle lift phase $(6.58 \mathrm{~mm})$ in Fig .5. Even some small deviations of peak values as the action of inertial loading exist at higher speed, the curves could still prove the validity of the dynamic model.

As shown in Fig .6. the comparison of various valve lifts at different speeds shows that the CVVA mechanism has excellent dynamic characteristics for the working condition of high lift phase $(9.91 \mathrm{~mm})$. Near valve closing time, there is small sign of harmful bounce at 3600 camshaft rpm, which predicts the limit speed of the CVVA mechanism is close to 3600 camshaft rpm, that covers the whole speed range of engine. The working condition of high lift phase $(9.91 \mathrm{~mm})$ could cover the high load of engine and also greatly enhance driving performance of automobile engine.

Peak value of valve acceleration is usually considered as a constraint value in the design of cam profile, and it also plays an important role in controlling the maximum contact stress between components. So the valve acceleration is an important parameter to evaluate the dynamic behavior of the valve train systems.

The curves of valve acceleration for different lift phases are shown from Fig .7 to Fig .9. The design values and simulation results have the same trends for different lift phases, which could prove the validity of the dynamic model in VALDYN. Some obvious vibrations happen in the negative acceleration of low lift compare to other lifts, and there are obvious overshoots of valve accelerations compared to the design value at the first positive peak for different lift phases, which indicates the internal vibration of valve train system with its natural frequency. The estimated natural frequency of the CVVA system is around $700 \mathrm{~Hz}$, which is much lower than that of conventional $\mathrm{OHC}$ valve trains. Natural frequency drop is inevitable because of increased moving mass and decreased system stiffness. In contrast, the high frequency vibration at the end of the valve closing event is due to the impact between the valve and valve seat. As shown in Fig .9, large acceleration at 3600 camshaft rpm after the valve closing 
corresponds to the impact of valve seating due to the valve bouncing.

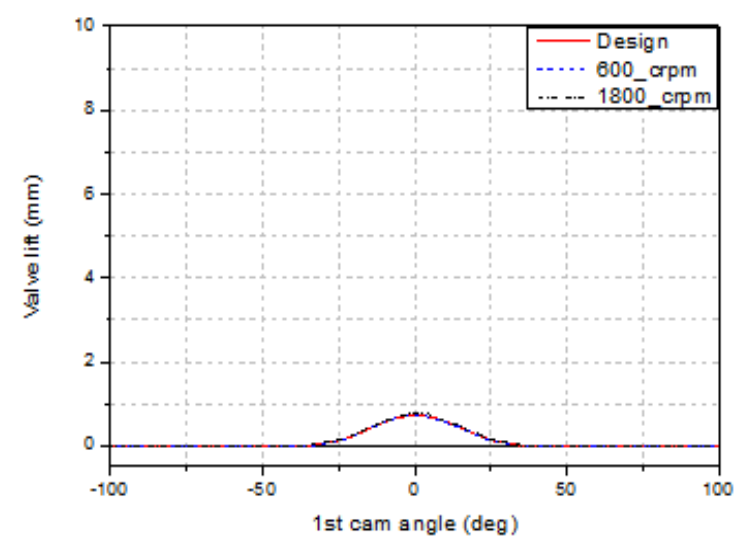

Figure 4. Valve lifts for low lift phase $(0.72 \mathrm{~mm})$

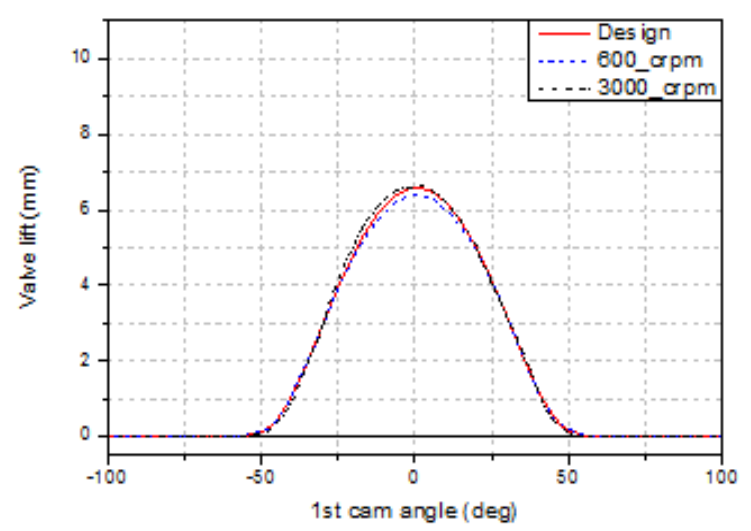

Figure 5. Valve lifts for middle lift phase $(6.58 \mathrm{~mm})$

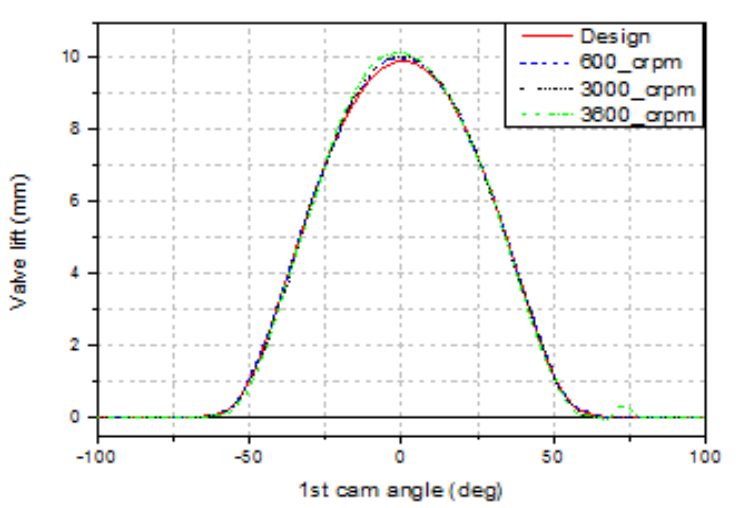

Figure 6. Valve lifts for high lift phase $(9.91 \mathrm{~mm})$

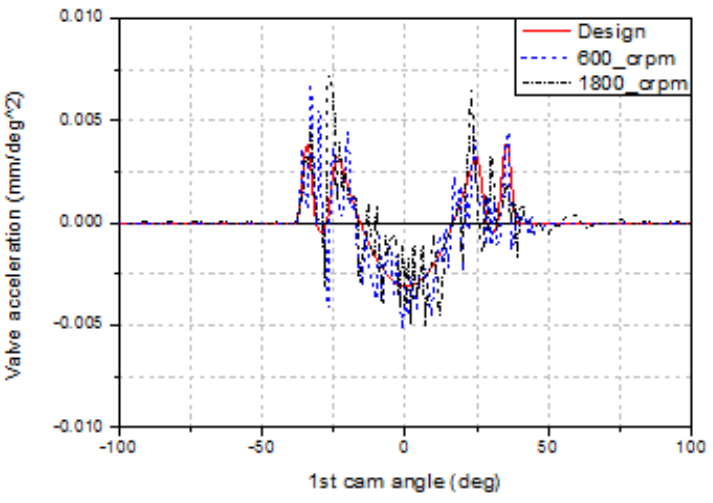

Figure 7. Valve acceleration for low lift phase $(0.72 \mathrm{~mm})$

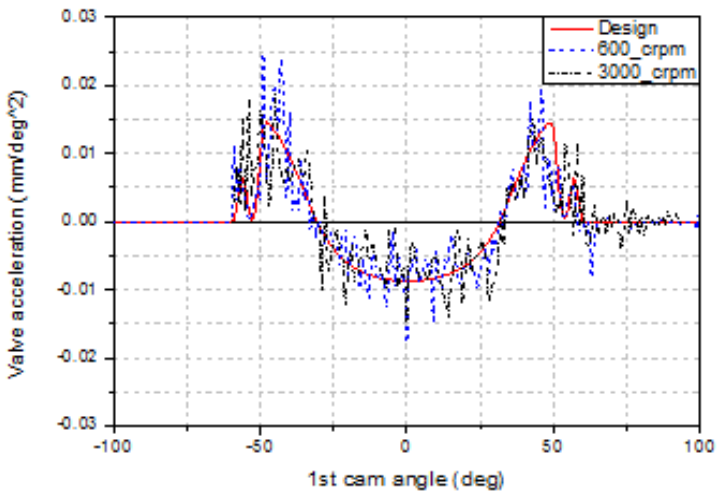

Figure 8. Valve acceleration for middle lift phase $(6.58 \mathrm{~mm})$

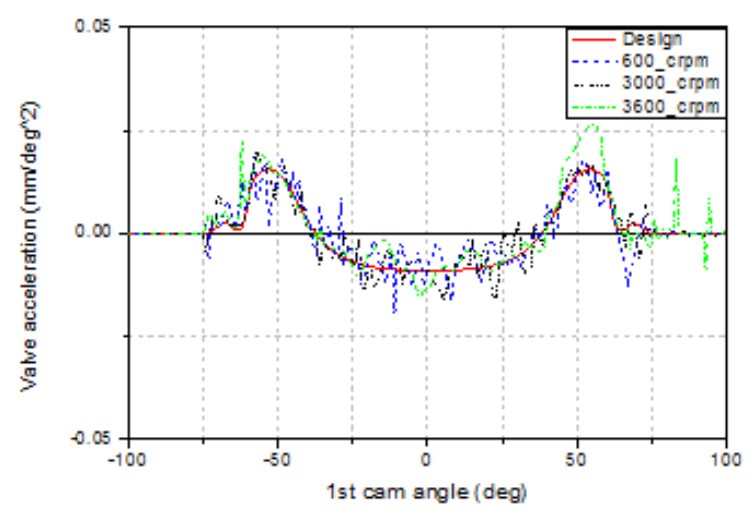

Figure 9. Valve acceleration for high lift phase $(9.91 \mathrm{~mm})$

\section{CONCLUSION}

A relatively simple four-bar linkage-type CVVA mechanism is proposed in this paper. The prototype CVVA mechanism is built and successfully operated up to 3600 camshaft rpm, and the usefulness of the CVVA mechanism dynamic model has been demonstrated. By comparison of the design and dynamic simulation results, the CVVA mechanism can achieve the initial design goal. The dynamic model in VALDYN software is applied to the development of testing and helps to optimize the properties of the CVVA mechanism, which is offering a broad space for the further development of combustion engines. 


\section{REFERENCES}

[1] WANG. Y, Introduction to engine valvetrains[M], USA: SAE International, 2007.

[2] ANGELES. J and LÓPEZ-CAJÚN. C. S, Optimization of cam mechanisms[M], Netherlands: Kluwer Academic Publishers, 1991.

[3] S. Takemura and S. Aoyama, "A study of a multiple-link continuously variable valve event and lift (VVEL) System," SAE Paper No. 2008-01-1719.

[4] R. Huber, P. Klumpp and H. Ulbrich, "Dynamic analysis of the Audi valvelift system," SAE Technical Paper series No. 2010-011195.

[5] Fujita. T, Onogawa. K, Kiga. S, Mae. Y and Akasaka. Y, "Development of innovative variable valve event and lift (VVEL) system," SAE Paper No. 2008-01-1349.
[6] Kyoung-Pyo. H, Donghee. H and Woo. T. K, "Development of continuously variable valve lift engine," SAE Paper No. 2010-011187

[7] Bukovnik. S, Tigran. P, Thomas. R and Wlofgang. H, "New kinematic design methodology and dynamic simulation of continuously variable valve lift (CVVL) system," SAE Paper No.2010-01-1202

[8] Ha. K, Han. D and Kim W.T, "Development of continuously variable valve lift engine," SAE Paper No. 2010-01-1187.

[9] Gecim. B, and Raghavan. M, "Simulation and test results for several variable-valve-actuation mechanisms," SAE Paper No. 2009-01-0229.

[10] Xiaozhen. Q and Dojoong. K, "Kinematic Design and Analysis of a Four-bar Linkage-type Continuously Variable Valve Actuation Mechanism," mechanism and machine theory, Vol.57, pp.111-125. 